\title{
APLIKASI METODE ROTATED GUMBEL COPULA UNTUK MENGESTIMASI VALUE AT RISK PADA INDEKS SAHAM PASAR ASIA
}

\author{
Ikhsan $\mathrm{Akbar}^{1 \S}$, Komang Dharmawan ${ }^{2}$, Ni Made $\mathrm{Asih}^{3}$ \\ ${ }^{1}$ Program Studi Matematika, Fakultas MIPA - Universitas Udayana [Email: ikhsanrabka15@gmail.com] \\ ${ }^{2}$ Program Studi Matematika, Fakultas MIPA - Universitas Udayana [Email: dharmawan.komang@gmail.com] \\ ${ }^{3}$ Program Studi Matematika, Fakultas MIPA - Universitas Udayana [Email: madeasih@unud.ac.id] \\ ${ }^{\S}$ Corresponding Author
}

\begin{abstract}
Value at Risk is a tool used to calculate the value of risk in investing. The purpose of this study was to estimate VaR in the portfolio using the rotated Copula Gumbel approach, which originated from the Archimedean copula family. Copula can provide an overview of the relationship between random VaRiables on a quantil scale which is very useful in explaining the interrelationships in extreme events. This VaR calculation is used in portfolios from the Indonesian stock index (JKSE), Malaysia (KLSE), Singapore (STI), and South Korea (KOSPI), in the period of June 1, 2016 to June 1, 2018 (519 data). VaR is calculated using a daily period with a confidence level of $99 \%$. So that the VaR of each portfolio is obtained, JKSE-KLSE is 1.41\%, JKSE-STI is 1.38\%, JKSE-KOSPI is 1.39\%, KLSESTI is 1.44\%, KLSE-KOSPI is 1.42\%, KOSPI-STI is 1.48\%. The highest risk level that can be derived from the portfolio contains a combination of the Singapore stock index (STI) and the South Korean stock index (KOSPI).
\end{abstract}

Keywords: Portofolio, rotated Gumbel copula, Value at Risk.

\section{PENDAHULUAN}

Saat ini banyak cara investor melakukan investasi seperti pertimbangan menggunakan portofolio untuk mendapatkan keuntungan dan menambah kekayaan. Namun, investasi juga tidak selalu bisa memberikan harapan pada investor untuk mendapatkan uang. Pertimbangan utama bagi pemilik dana (investor) dalam mengoptimalkan keputusan investasi adalah memaksimumkan tingkat imbal hasil investasi tingkat pengembalian (return) pada risiko investasi tertentu (Sunaryo, 2007).

Portofolio dinyatakan sebagai sekumpulan aset yang dimiliki untuk tujuan ekonomis tertentu. Konsep dasar yang dinyatakan dalam portofolio adalah bagaimana mengalokasikan sejumlah dana tertentu pada berbagai jenis investasi yang akan menghasilkan keuntungan yang optimal (Bierman, 1998).

Investasi yang ada mengandung ketidakpastian atau risiko, maka dari itu investor disarankan mempertimbangkan menggunakan portofolio. Investor tidak mengetahui apa hasil yang akan didapatkan dari investasi yang dilakukan. Risiko yang dihadapi oleh investor sebanding dengan keuntungan yang diharapkan, jika mengharapkan mendapatkan keuntungan yang tinggi maka investor harus siap mendapatkan risiko yang tinggi juga.

Risiko dalam investasi adalah ketidakpastian yang dihadapi karena harga suatu aset atau investasi menjadi lebih kecil daripada return investasi yang diharapkan. Risiko yang terjadi dapat berupa penurunan harga saham, inflasi, peningkatan suku bunga, dan lain-lain. Banyak hal yang memengaruhi timbulnya risiko sehingga diperlukan suatu alat ukur risiko untuk mempermudah meminimalkan risiko terkait dengan investasi yang dilakukan.

Para investor lebih memilih berinvestasi di negara yang memiliki reputasi baik dalam dunia perinvestasian karena harapan akan keuntungan yang didapat lebih terjamin. Contoh negara yang difavoritkan para pemilik modal dunia adalah Singapura. Hasil survei Forum Ekonomi Dunia (World Economic Forum) mengenai indeks daya saing global menyatakan bahwa Indonesia 
menduduki peringkat ke-36 dari 137 negara yang masuk dalam daftar GCI (Global Competitiveness Index) tahun 2017. Peringkat ini merupakan peningkatan dari peringkat tahun sebelumnya yang menempatkan Indonesia pada posisi 41. Namun, posisi Indonesia masih tertinggal dari negara-negara ASEAN seperti Malaysia (peringkat ke-23) dan Singapura (peringkat ke-3).

Pasar saham setiap negara di seluruh dunia saling berkaitan satu sama lain, tak terkecuali pasar saham Indonesia, Korea Selatan, Malaysia, dan Singapura. Pada umumnya, mengelola suatu risiko mengacu pada keterkaitan dari return harus memenuhi asumsi-asumsi, seperti berdistribusi simetris, distribusi return tidak memiliki ekor gemuk (heavy tail), serta hubungan antarvariabel harus linier. Penjelasan terhadap asumsi-asumsi itu sampai saat ini belum didapatkan, sehingga model alternatif yang memiliki struktur kebergantungan lebih fleksibel dan memiliki distribusi marginal yang lebih bebas sangat diperlukan (Franke, 2008). Disebutkan juga oleh Embrechts, et al. (2001), bahwa mengasumsikan harga saham yang membentuk portofolio memiliki struktur korelasi linear akan dapat menimbulkan masalah yang serius dalam pengambilan keputusan. Model alternatif yang memiliki karakteristik seperti disebutkan di atas adalah copula. Copula dapat mengatasi masalah-masalah yang disebutkan di atas dan dapat diterapkan dalam kasus yang lebih luas (Nelsen, 1999).

Copula memiliki konsep sebagai alat untuk menggabungkan beberapa distribusi marginal menjadi distribusi gabungan. Keluarga copula yang populer antara lain keluarga copula eliptik dan keluarga Archimedian copula. Anggota dari keluarga copula eliptik adalah Gaussian copula dan t-Student copula. Sedangkan anggota dari keluarga Archimedian copula adalah Clayton copula, Frank copula, dan Gumbel copula.

Perhitungan nilai risiko dalam berinvestasi sangat penting agar investor dapat mempersiapkan cadangan dana untuk menanggulangi kerugian. Salah satu cara untuk mendapatkan nilai risiko yaitu menggunakan Value at Risk (VaR). Perhitungan menggunakan $\mathrm{VaR}$ merupakan bagian dari manajemen risiko. VaR pada saat ini banyak diterima, diaplikasikan dan dianggap sebagai metode standar dalam mengukur risiko. VaR dapat didefinisikan sebagai estimasi kerugian maksimum yang akan didapat selama periode waktu (time period) tertentu dalam kondisi pasar normal pada tingkat kepercayaan tertentu (Jorion, 2007).

Pada penelitian ini, peneliti membahas nilai risiko dari indeks saham Indonesia, Korea Selatan, Malaysia, dan Singapura. Data yang akan diolah adalah data harga penutupan harian. Karena copula dapat memodelkan keterkaitan satu variabel acak dengan variabel acak lainnya, maka peneliti menggunakan salah satu fungsi copula dari keluarga Archimedian copula yang dirotasi yaitu rotated Gumbel copula.

\section{METODE PENELITIAN}

Penelitian ini menggunakan data sekunder, yaitu data dari harga penutupan indeks saham (close price) harian pada periode 1 Juni 2016 sampai 1 Juni 2018. Indeks saham yang digunakan yaitu indeks saham Indonesia, Korea Selatan, Malaysia, dan Singapura yang didapat dari http://www.investing.com . Pengolahan data pada penelitian ini menggunakan Software Microsoft Excel 2016 dan Matlab R2013a. Adapun tahapan penyelesaian dalam penelitian ini yaitu:

1. Mengumpulkan data histori harian harga saham pada periode 1 Juni 2016 sampai 1 Juni 2018 .

2. Memplot data indeks saham yang digunakan untuk melihat pergerakan indeks saham Indonesia, Korea Selatan, Malaysia, dan Singapura.

3. Menghitung nilai return dari data indeks saham Indonesia, Korea Selatan, Malaysia, dan Singapura. Return dihasilkan dari selisih harga saham yang akan datang dengan saham hari ini yang dirumuskan sebagai berikut

$$
r_{i, t}=\frac{S_{i, t+1}-S_{i, t}}{S_{i, t}}
$$

4. Melakukan estimasi parameter pada fungsi rotated Gumbel copula dihitung menggunakan metode maksimum likelihood estimation (MLE) yang dirumuskan sebagai berikut

$$
\begin{aligned}
& \left(\hat{\alpha}_{1}^{M L E}, \hat{\alpha}_{2}^{M L E}, \cdots, \hat{\alpha}_{d}^{M L E}, \hat{\theta}_{d}^{M L E}\right) \\
& =\arg \max _{\alpha_{1}, \alpha_{2}, \cdots, \alpha_{d}, \theta} \sum_{j=1}^{n} \log c
\end{aligned}
$$


$\left(F_{1}\left(x_{1}^{(j)} ; \alpha_{1}\right), F_{2}\left(x_{2}^{(j)} ; \alpha_{2}\right), \cdots, F_{d}\left(x_{d}^{(j)} ; \alpha_{d}\right) ; \theta\right)$

$+\sum_{i=1}^{d} \sum_{j=1}^{n} \log f_{i}\left(x_{i}^{(j)} ; \alpha_{i}\right) \cdot$

5. Setelah estimasi parameter diketahui maka dilakukan simulasi dengan menggunakan sofware Matlab R2013a berbasis rotated Gumbel copula untuk mendapatkan data yang menyerupai data aslinya.

6. Melakukan perhitungan nilai Value at Risk pada portofolio yang digunakan. Langkahlangkah yang dapat dilakukan sebagai berikut:

a. Tentukan jangka waktu VaR.

b. Tentukan bobot masing-masing saham pada portofolio.

c. Menentukan nilai VaR dengan selang kepercayaan $99 \%$ dengan persamaan sebagai berikut

$$
\operatorname{VaR}=\left(1-e^{\gamma}\right) V_{t}
$$

\section{HASIL DAN PEMBAHASAN}

\subsection{Analisis Data}

Penentuan Value at Risk kali ini menggunakan pendekatan rotated Gumbel copula. Data yang dipakai dalam proses pembahasan penelitian ini adalah data harga penutupan indeks saham (close price) pada periode 1 Juni 2016 sampai 1 Juni 2018. Indeks saham yang digunakan yaitu indeks saham Indonesia (JKSE), indeks saham Malaysia (KLSE), indeks saham Singapura (STI), dan indeks saham Korea Selatan (KOSPI), dengan masing-masing jumlah data indeks saham sebanyak 519 data, indeks saham disajikan pada Gambar 1.

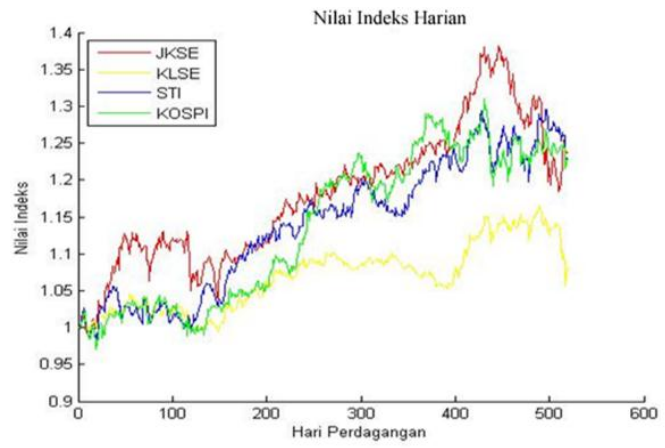

Gambar 1. Plot Data Indeks Saham Indonesia (JKSE), Malaysia (KLSE), Singapura (STI), dan Korea Selatan (KOSPI).
Berdasarkan Gambar 1. plot data indeks saham menunjukkan pergerakan harga yang relatif sama dari setiap indeksnya. Data dari setiap indeks saham telah dinormalisasi atau distandarkan untuk memfasilitasi pergerakan dan perbandingan kinerja masing-masing indeks saham yang digunakan.

Proses analisis penentuan Value at Risk ini menggunakan data indeks saham yang diubah menjadi tingkat pengembalian (return). Tingkat pengembalian (return) didapatkan dari data masing-masing indeks saham yang ditentukan dari harga penutupan harian indeks saham. Data return yang dihasilkan dari setiap indeks saham sebanyak 518 data. Dari hasil penentuan nilai tingkat pengembalian (return) harian setiap indeks saham yang digunakan, disajikan pada Gambar 2.
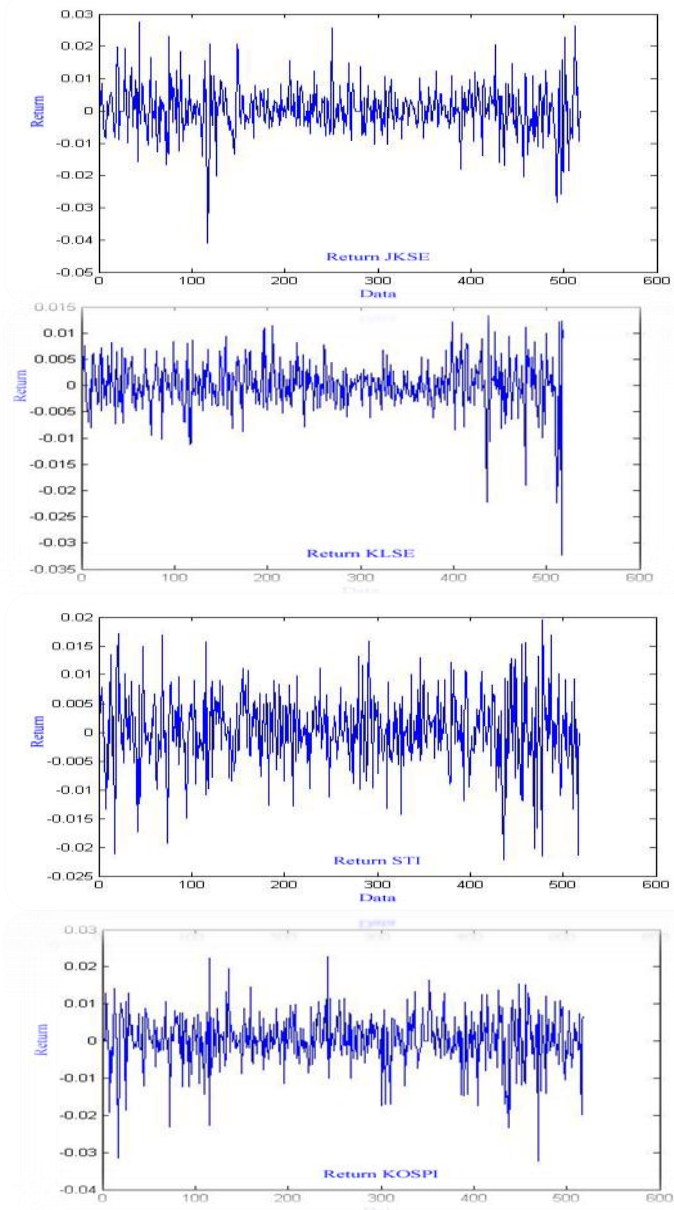

Gambar 2. Plot nilai return JKSE, KLSE, STI, dan KOSPI

Setelah mendapatkan hasil dari nilai return untuk setiap data indeks saham Indonesia (JKSE), indeks saham Malaysia (KLSE), indeks saham Singapura (STI), dan indeks saham Korea Selatan (KOSPI), dilakukan penggabungan 
setiap dua indeks saham sehingga menjadi portofolio. Perhitungan dengan menggunakan pendekatan rotated Gumbel copula yang bersifat multivariat mengharuskan penggabungan data, sehingga dihitung nilai return dari setiap penggabungan atau portofolio yang digunakan dan dapat disajikan seperti pada Gambar 3.

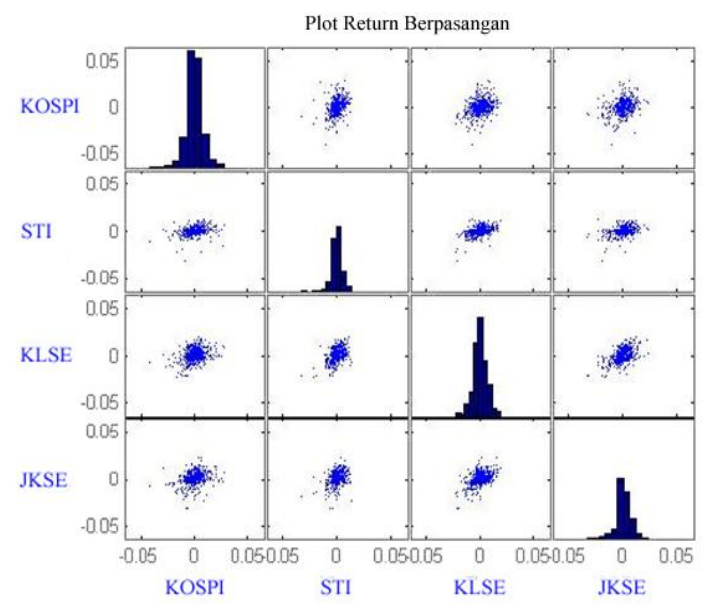

Gambar 3. Plot Return Berpasangan Indeks Saham atau Portofolio.

Menurut Gambar 3. dapat dilihat bahwa dihasilkannya gambaran sebaran setiap gabungan indeks saham dari indeks saham Indonesia (JKSE), indeks saham Malaysia (KLSE), indeks saham Singapura (STI), dan indeks saham Korea Selatan (KOSPI).

\subsection{Estimasi Parameter}

Estimasi parameter dilakukan untuk mendapatkan nilai parameter yang akan digunakan pada simulasi data. Untuk melakukan estimasi parameter pada fungsi rotated Gumbel copula dalam penelitian ini dihitung menggunakan metode maksimum likelihood estimation (MLE), perhitungan dilakukan dengan menggunakan sofware Matlab R2013a. Estimasi parameter rotated Gumbel copula untuk Indeks saham Indonesia (JKSE) dan Indeks saham Malaysia (KLSE) diperoleh nilai parameternya sebesar 1,3272. Untuk mendapatkan nilai parameter dari indeks saham lainnya menggunakan cara yang sama, dengan yang dilakukan pada nilai parameter indeks saham Indonesia (JKSE) dan indeks saham Malaysia (KLSE).

Setelah mendapatkan nilai parameter, penelitian ini bisa dilanjutkan dengan melakukan simulasi data untuk menemukan data yang menyerupai data aslinya. Nilai parameter dari masing-masing gabungan indeks saham yang telah didapat dari perhitungan Matlab R2013a tersaji pada Tabel 1 .

Tabel 1. Nilai Parameter indeks saham Indonesia, Malaysia, Singapura, dan Korea Selatan.

\begin{tabular}{|c|c|c|c|c|}
\hline $\begin{array}{c}\text { Indeks } \\
\text { Saham }\end{array}$ & $\begin{array}{c}\text { Indonesia } \\
\text { (JKSE) }\end{array}$ & $\begin{array}{c}\text { Malaysia } \\
\text { (KLSE) }\end{array}$ & $\begin{array}{c}\text { Singapura } \\
\text { (STI) }\end{array}$ & $\begin{array}{c}\text { Korea } \\
\text { Selatan } \\
\text { (KOSPI) }\end{array}$ \\
\hline JKSE & & 1,3272 & 1,2302 & 1,2647 \\
\hline KLSE & 1,3272 & & 1,3920 & 1,3447 \\
\hline STI & 1,2302 & 1,3920 & & 1,4826 \\
\hline KOSPI & 1,2647 & 1,3447 & 1,4826 & \\
\hline
\end{tabular}

Sumber: Data diolah (2019)

\subsection{Simulasi Data}

Simulasi data dilakukan untuk membangkitkan bilangan acak berbasis rotated Gumbel copula dengan parameter yang sudah diperoleh pada perhitungan sebelumnya. Simulasi ini dilakukan pada nilai tingkat pengembalian (return) pada masing-masing gabungan indeks saham. Simulasi pada penelitian ini dilakukan sebanyak 10.000 kali. Dengan melakukan simulasi simulasi sebanyak lebih dari data yang digunakan akan diperoleh nilai yang makin stabil.

Proses simulasi dilakukan dengan sofware Matlab R2013a pada masing-masing dua indeks saham yang digabungkan sehingga menjadi portofolio. Karena peneliti menggunakan empat indeks saham maka portofolio yang dibuat berasal dari empat indeks saham yang saling berpasangan, sampai semua indeks saham yang digunakan menjadi portofolio yang berbeda (enam portofolio). Setelah mendapatkan nilai return portofolio yang menyerupai nilai aslinya pada simulasi, masing-masing hasil simulasi return digunakan sebagai nilai untuk perhitungan Value at Risk. Perhitungan Value at Risk menggunakan bobot 0,5 untuk masingmasing indeks saham.

\subsection{Perhitungan Value at Risk}

Perhitungan VaR peneliti menentukan tingkat kepercayaan yang digunakan, tingkat kepercayaan yang digunakan untuk penelitian ini yaitu 99\%. Karena tingkat kepercayaan yang digunakan yaitu 99\%, maka VaR nya adalah 
nilai kuantil $99 \%$ dari return masing-masing portofolio yang telah diperoleh dari simulasi return yang telah dilakukan sebelumnya.

Dari hasil perhitungan yang telah dilakukan, peneliti mendapatkan nilai VaR dari masing-masing gabungan indeks saham yang digunakan. Seperti indeks saham Indonesia (JKSE) dan indeks saham Malaysia (KLSE), JKSE dan indeks saham Singapura (STI), JKSE dan indeks saham Korea Selatan (KOSPI), KLSE dan STI, KLSE dan KOSPI, STI dan KOSPI. Berikut ini adalah hasil dari nilai VaR masing-masing gabungan indeks saham yang disajikan pada Tabel 2.

Tabel 2. VaR portofolio dari indeks saham Indonesia, Malaysia, Singapura, dan Korea Selatan

\begin{tabular}{|c|c|c|c|c|}
\hline $\begin{array}{c}\text { Indeks } \\
\text { saham }\end{array}$ & $\begin{array}{c}\text { Indonesia } \\
\text { (JKSE) }\end{array}$ & $\begin{array}{c}\text { Malaysia } \\
\text { (KLSE) }\end{array}$ & $\begin{array}{c}\text { Singapura } \\
\text { (STI) }\end{array}$ & $\begin{array}{c}\text { Korea } \\
\text { Selatan } \\
\text { (KOSPI) }\end{array}$ \\
\hline JKSE & $1,41 \%$ & $1,41 \%$ & $1,38 \%$ & $1,39 \%$ \\
\hline KLSE & $1,48 \%$ & $1,44 \%$ & $1,44 \%$ & $1,42 \%$ \\
\hline STI & $1,38 \%$ & $1,48 \%$ & \\
\hline KOSPI & $1,39 \%$ & $1,42 \%$ & $1,48 \%$ \\
\hline
\end{tabular}

Sumber: Data diolah (2019)

Mengacu pada Tabel 2. dihasilkan nilai VaR dari setiap portofolio. VaR dari setiap portofolio memiliki nilai yang variatif. Bisa dilihat dari tabel tesebut bahwa gabungan dari masingmasing indeks saham memiliki tingkat risiko yang tidak jauh berbeda antara satu dengan yang lainnya. Diperoleh nilai risiko terendah dari portofolio berisikan indeks saham Indonesia (JKSE) dengan indeks saham Singapura (STI) sebesar $1,38 \%$ dan nilai risiko tertinggi pada portofolio berisikan gabungan dari indeks saham Korea Selatan (KOSPI) dan indeks saham Singapura (STI) sebesar $1,48 \%$.

\section{KESIMPULAN DAN SARAN}

\subsection{Kesimpulan}

Berdasarkan perhitungan dan pembahasan penelitian ini telah dilakukan prosedur atau langkah-langkah yang diperlukan dalam mengestimasi Value at Risk menggunakan pendekatan rotated Gumbel copula yaitu menganalisis data yang digunakan seperti Indeks saham Indonesia (JKSE), Indeks saham Malaysia (KLSE), Indeks saham Singapura (STI), dan Indeks saham Korea Selatan (KOSPI). Kemudian dilakukannya estimasi parameter pada setiap gabungan masing-masing dua indeks saham, setelah mendapatkan parameter dilakukan simulasi untuk membangkitkan bilangan acak berbasis parameter. Setelah melakukan simulasi, dilakukan perhitungan Value at Risk.

Estimasi Value at Risk pada portofolio menggunakan pendekatan rotated Gumbel copula menggunakan indeks saham yang digabungkan sehingga berisikan masingmasing dua indeks atau dijadikan portofolio pada tingkat kepercayaan $99 \%$ dan interval waktu harian. Value at Risk dari masingmasing portofolio diperoleh sebagai berikut, JKSE-KLSE sebesar 1,41\% , JKSE-STI sebesar 1,38\%, JKSE-KOSPI sebesar 1,39\% , KLSE-STI sebesar 1,44\% , KLSE-KOSPI sebesar $1,42 \%$, dan KOSPI-STI sebesar $1,48 \%$. Tingkat risiko tertinggi yang bisa didapat investor berada pada portofolio yang berisikan gabungan antara indeks saham Singapura (STI) dan indeks saham Korea Selatan (KOSPI) sebesar $1,48 \%$ dalam waktu persatu hari.

\subsection{Saran}

Berdasarkan dari pembahasan pada penelitian ini, untuk penelitian selanjutnya disarankan menggunakan metode copula dari keluarga copula lainnya, seperti keluarga copula eliptik dan keluarga Archimedian copula. Anggota dari keluarga copula eliptik adalah Gaussian copula dan t-Student copula. Sedangkan anggota dari keluarga Archimedian copula adalah Clayton copula, Frank copula, dan Gumbel copula, atau copula lainnya yang bisa dirotasi. Sehingga dapat dilihat perbandingan dan keakuratan hasil masing-masing metode yang digunakan.

\section{DAFTAR PUSTAKA}

Bierman, H. 1998. A Utility Approach to the Portfolio Allocation Decision and the Investment Horizon. Journal of Portfolio Management, 25, 81-87.

Embrechts, P., Hoeing, A., \& Juri, A. 2001. Using copulae to bound the value-at-risk for functions of dependent risks. ETH Zurich, preprint.

Franke, J., Wolgang, K., \& Hafner, C.. 2008. Statistics of Financial Markets. Springer: Berlin.

Jorion, Philippe. 2007. Value at Risk: The New 
Benchmark For Managing Financial Risk. Third Edition. Singapore: McGraw-Hill International Edition.

Nelsen, R. B. 1999. "An Introduction to Copulas", 2nd ed, Springer, New York.

Ramadhan, B. 2017. Good News For Indonesia. https://www.goodnewsfromindonesia.id/201 7/10/04/tingkat-daya-saing-negara-negaradunia-tahun-2017-2018-indonesia-naikperingkat. 22 Oktober 2018.

Sunaryo, T. 2007. Manajemen Risiko Finansial. Jakarta: Salemba Empat. 